\title{
Strengthening Effects of RC Flexural Members with FRP Sheets Affected by Adhesive Layers
}

\author{
F R P シート接着補強曲げ部材の補強効果に及ぼす接着層の影響
}

\author{
Hedong Niu* and Zhishen $\mathrm{Wu}^{* *}$ \\ 牛 赫東 呉 智深 \\ * Dr. of Eng., JSPS Postdoctoral Fellow, Dept. of Urban \& Civil Eng., Ibaraki University \\ (4-12-1, Nakanarusawa-cho, Hitachi, Ibaraki 316-8511) \\ ** Dr. of Eng., Professor, Dept. of Urban \& Civil Eng., Ibaraki University \\ (4-12-1, Nakanarusawa-cho, Hitachi, Ibaraki 316-8511)
}

\begin{abstract}
Fiber reinforced polymers (FRP) can be bonded to the tension face of concrete structures to enhance the structural performance via a thin layer of adhesive and this has been confirmed to be a very promising rehabilitation method worldwide. Proper understanding of effects of the adhesive properties on strengthening of RC members with FRP sheets is very essential and urgent to the FRP bonding technique. Recently, some interesting experiments have been conducted and it is found that the FRP strengthening effects can be improved by adding flexible layer or rubber modifier to the epoxy adhesive for some cases. To clarify these experimental phenomena, in this study, a finite element analysis based on nonlinear fracture mechanics is performed to investigate effects of the interfacial mechanical properties such as stiffness, local bond strength and fracture energy on the structural performance of FRP-strengthened $\mathrm{RC}$ beams. Through conducting parametric study on the strengthened $\mathrm{RC}$ beam with two possible crack patterns accompanied by debonding failure, it is concluded that the structural load-carrying capacity is only governed by the interfacial fracture energy. This study provides a good implication for future practical application.
\end{abstract}

Key Wonds: fiber reinforced polymers (FRP), strengthen/retrofit, adhesive, bond, mechanism, interfacial fracture energy

\section{Introduction}

At the beginning of a new century, need for repair and strengthening of deteriorated, damaged, and substandard infrastructure has become one of the most important challenges confronting the repair and rehabilitation industries worldwide. Traditionally, structural rehabilitation was accomplished by overlaying and jacketing method, external cable method or bonding and jacketing method of steel plates to the tension face of the deficient members. However, these methods often suffer from inherent disadvantages ranging from difficult application procedures to lack of durability, which demands the invention of new methods and materials for rehabilitation. The advances in the material industry have resulted in the development of nonmetallic fiber reinforced polymers (FRP) that possess many beneficial characteristics such as high strength- and stiffness-to-weight ratio, high corrosion resistance, electromagnetic neutrality, inherent tailorability. These high-performance materials can be externally bonded to the tension face of the concrete structures to be strengthened via a thin layer of adhesive (commonly, epoxy resin) and thus enhance the corresponding service performances. Such kind of bonding technique is very easy to handle by hand without needing additional equipment and has been accepted as an innovative and promising method for the maintenance, rehabilitation and upgrading of existing infrastructure in the world.

The pivot of the FRP bonding technique is to ensure good performance of the adhesive layer, through which stresses can be transmitted from concrete substrate to FRP. Any failure in this stress transmission zone may invalidate the composite action between concrete and 
FRP and lead to a brittle, catastrophic failure without foreboding prior to achieving the expected strengthening effects. Such interfacial fractures include debonding at the interface between concrete and adhesive, or between adhesive and FRP, or within the adhesive, where fracture within the concrete adjacent to the interface between concrete and adhesive is mostly observed in the experiments of FRP-strengthened RC beams. Therefore, it is not possible to efficiently apply FRP bonding technique to structural rehabilitation without taking a good grasp of influencing mechanism of bond properties on strengthening effects.

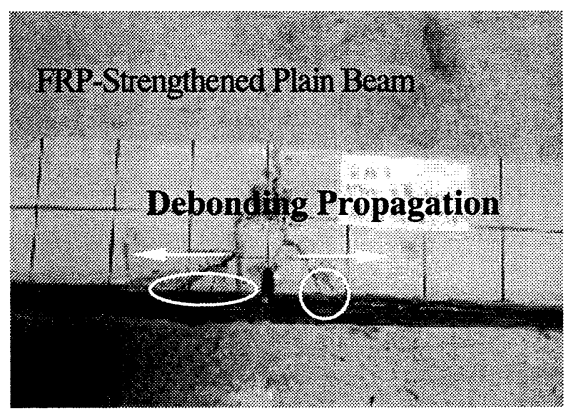

(a) Centralized Crack Pattern

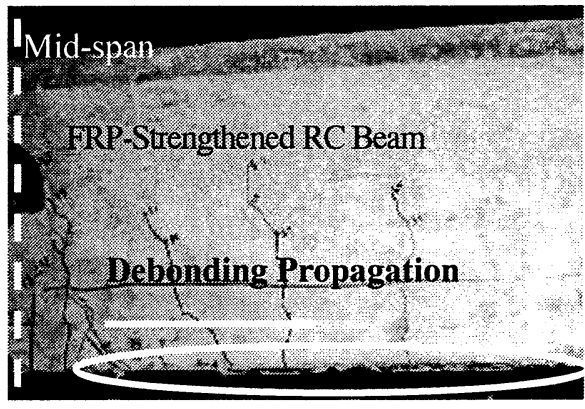

(b) Distributed Crack Pattern

Fig.1 Debonding of FRP from Ends of Flexural Cracks

Typical bond failure modes can be grouped into three categories: delamination of FRP from the plate end due to high stress concentrations, FRP peeling-off from the ends of shear cracks and debonding of FRP from the ends of flexural cracks around the midspan. Among them, the third one is regarded as the most dominant failure mode in the strengthened RC beams with thinner FRP sheets (Fig. 1). So far much research has been carried out to investigate the bond and debonding mechanisms of pure shear test of FRP ${ }^{1)}{ }^{2)}$ and bending test of FRP-strengthened R/C beams ${ }^{3), 4), 5)}$. Nishida et al. ${ }^{1)}$ conducted uniaxial tension test to investigate a series of influencing factors such as concrete strength, FRP width, FRP modulus and adhesive modulus on the bond mechanism between FRP sheet and concrete. They used the experimental data to characterize the relationship between bond stress and the relative displacement by a bilinear model with softening branch. It was found that the epoxy with low modulus may shift the failure mode from debonding to rupture of FRP and the bond behavior can be changed to a curve similar to traditional bond-slip curve between steel and concrete. Yoshizawa et al. ${ }^{2)}$ performed an experimental program of the shear test between FRP sheet and concrete. The interfacial fracture energies and the relationship between the local shear stress and the relative shear displacement along the FRP-concrete interface were identified. It was pointed out that the local interfacial shear stress distribution, effective bonding length, and initiation and propagation of interfacial crack could be well described by using the interfacial shear-displacement relationship with linearly ascending and descending branches. $\mathrm{Wu}$ and $\mathrm{Niu}^{3), 4)}$ adopted linear shear-displacement relationship to investigate the effects of flexural cracks on the interfacial shear stresses for several load cases based on linearly elastic beam theory and developed an energy-based methodology to predict debonding initiation and final debonding failure of the retrofitted beam. Recent studies have demonstrated that proper understanding and modeling of FRP-concrete interface-related phenomena and failures can be improved via the application of fracture mechanics theories. In view of this, Niu and $\mathrm{Wu}^{5}$ ) performed numerical analyses based on nonlinear fracture mechanics to mainly investigate the influence of flexural crack spacing on debonding behavior and failure mechanism of FRP-strengthened R/C beams.

Recently, some interesting experiments have been carried out to improve the FRP strengthening effects by using a more flexible adhesive layer with a low shear modulus and high extension strain ${ }^{6)}$, ${ }^{7}$. Maeda et $\mathrm{al}^{6}$ ) conducted bending experiments on carbon fiber sheets (CFS)-strengthened RC beams with a highly flexible layer added between concrete and CFS. It was found that the flexible layer could relieve the stress concentration on CFS and improve the bonding behavior of CFS, which improves the strengthening effects of CFS. It should be noted that the strengthening effects of CFS did not increase with the thickness of flexible layer. Gao et al. ${ }^{7)}$ reported an experimental study regarding the influence of adhesive properties on mechanical/structural behavior of RC beams strengthened with FRP sheets. The FRP sheets were bonded to the concrete beams using epoxy adhesive containing rubber modifier of different contents. The experimental results showed that the rubber modifier could increase both the load-carrying capacity and the 


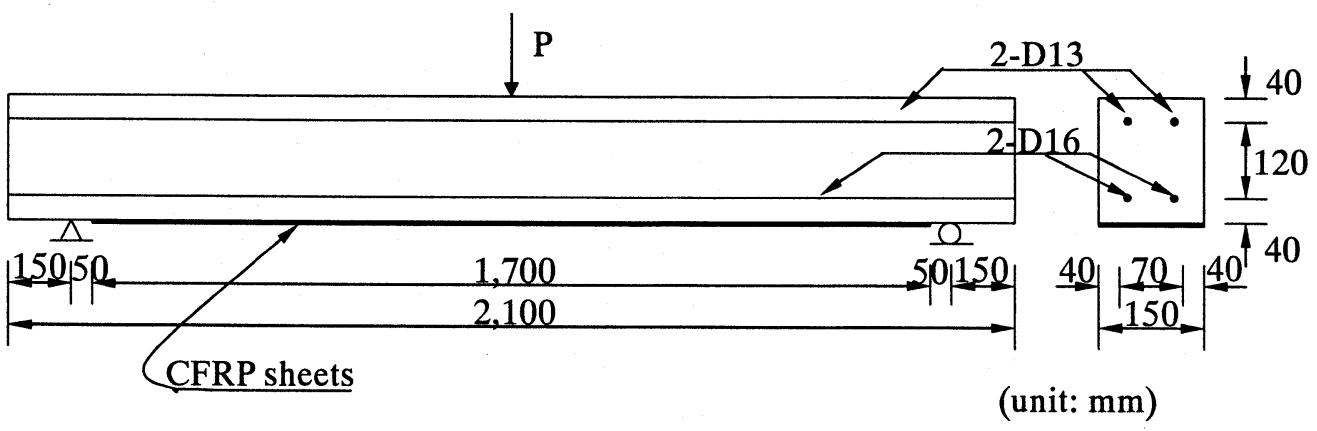

Fig. 2 Details of FRP-strengthened RC Beam

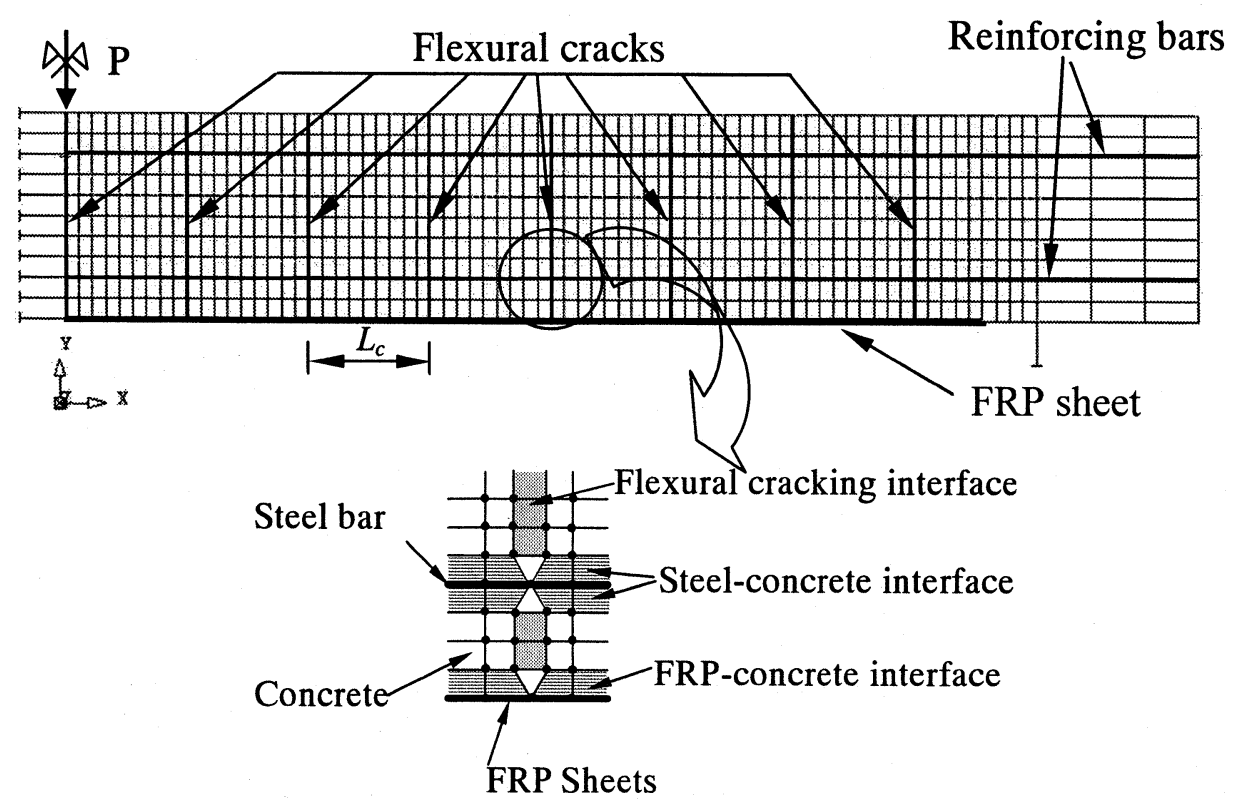

Fig. 3 Two-dimensional Discretization Model for FRP-strengthened RC Beam

corresponding displacement. Among the specimens, not all beams strengthened with rubber modified epoxy adhesive can be improved by compared to the control beam strengthened with a conventional neat epoxy resin. Till now, influencing mechanism of adhesive properties on the FRP strengthening effects remains yet unknown. To this end, in this study, it mainly aims at clarifying the effects of adhesive properties such as stiffness, local bond strength and fracture energy on the FRP strengthening effects from viewpoint of nonlinear fracture mechanics. Through conducting parametric study on the strengthened $\mathrm{RC}$ beams with two possible crack patterns accompanied by debonding failure, it is concluded that the structural load-carrying capacity is only governed by interfacial fracture energy.

\section{Mechanical Model}

As shown in Fig. 2, a FRP-strengthened RC beam consists of three parts: concrete, reinforcing bars and FRP sheets. To simulate the real response of the composite beam, it is necessary to establish appropriate mechanical models for considering the crack propagation behavior in concrete, bond-slip behavior between reinforcing bars and concrete and bonding behavior along the adhesive layer.

As reviewed in Introduction, debonding of FRP from ends of flexural cracks of concrete is the most dominant failure mode in flexural strengthening of RC beams with thinner FRP sheets and may be more dependent on the bonding properties. In Fig. 1, two crack patterns can be observed for such debonding failure: centralized and distributed crack patterns. For simplicity of the problem, discrete crack model is used to simulate the crack propagation in concrete. FRP sheets, reinforcing bars are considered as discrete elements connected to concrete by interface elements. The adhesive properties can be reflected in the bond stress-relative displacement relationship between concrete and FRP sheets. The detailed mesh can be depicted in Fig. 3. In this model, no diagonal flexural or shear crack is taken into account and the flexural cracks are assumed to be vertical along the depth of the beam. They cannot develop at the locations other than those prescribed in advance. 

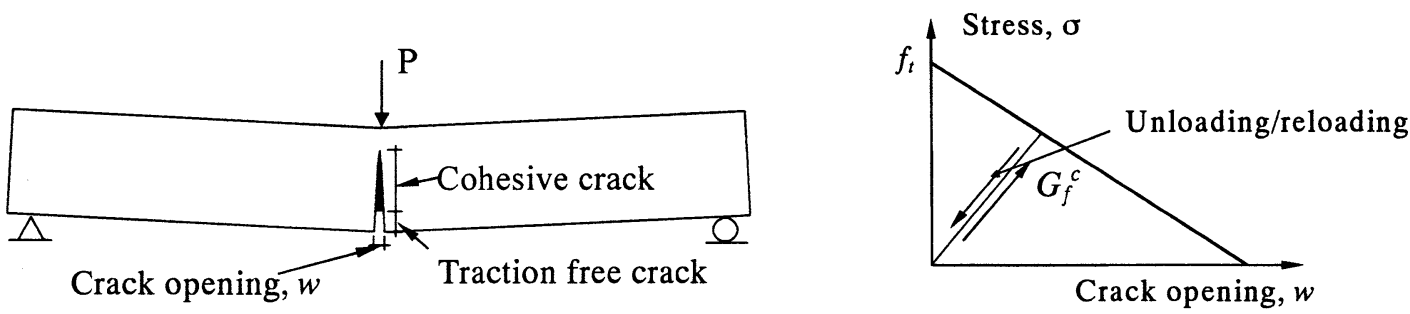

Fig. 4 Linear Tension Softening Model for Concrete

\subsection{Concrete Cracking and Interface Models}

In what follows, detailed descriptions are made for modeling concrete cracking, bond-slip relationship between reinforcing bars and concrete, and bond behavior between FRP sheet and concrete.

\section{(1) Discrete Cracking Model of Concrete}

In order to simulate the initiation and propagation of flexural cracks, a discrete cracking model is adopted to take the tension softening effect into account. It is assumed that flexural cracks are vertical along the depth of the beam and cannot develop at the locations other than those prescribed in advance.

According to Hillerborg et al. ${ }^{8)}$, flexural cracking can be modeled with discrete cohesive crack, as shown in Fig. 4. A crack in concrete is composed of two zones: one is the traction-free crack, where no forces are transferred and crack surfaces are wholly separated and the other is the cohesive crack where forces are followed by a given softening curve. Herein a linear softening curve is adopted to model the mode I tension softening behavior of concrete. In this model shown in Fig. 4, the cohesive crack, preceding the formation of real crack, is assumed to be initiated if the tensile stress reaches the tensile strength $f_{t}$; the macro-crack (real crack) is formed when the energy required to create one unit area of crack is met. The area below the curve is the fracture energy $G_{f}^{c}$. Unloading and reloading behaviors are modeled by a secant path, which means that upon unloading the stress follows a straight line back to the origin. After cracking no shear stress is transferred along the interface of crack.

\section{(2) Steel-Concrete Interface Model}

The bond mechanism between concrete and deformed steel was investigated theoretically and experimentally by Morita et al. ${ }^{9}$ as an early study. A bond-slip model proposed by them is used to simulate the interfacial behavior between concrete and the deformed reinforcing bars in this study, as depicted in Fig. 5. Unloading and reloading is modeled using a secant approach. Upon a slip reversal, a straight line back to the origin is followed.

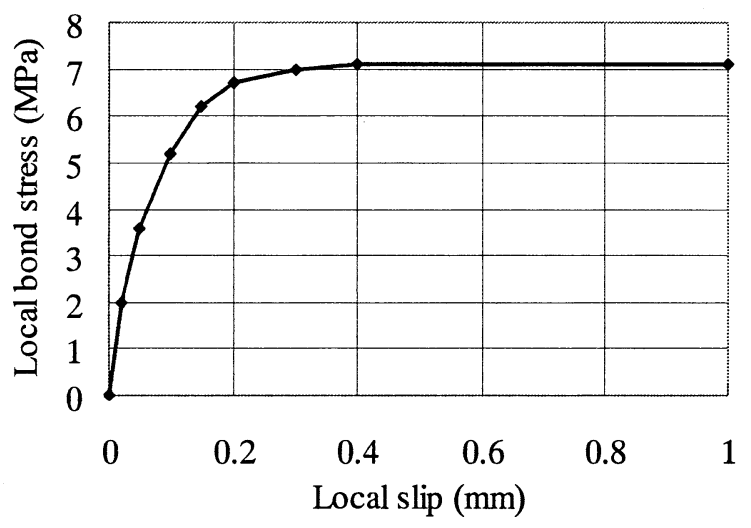

Fig. 5 Bond-Slip Model for Steel-concrete Interface

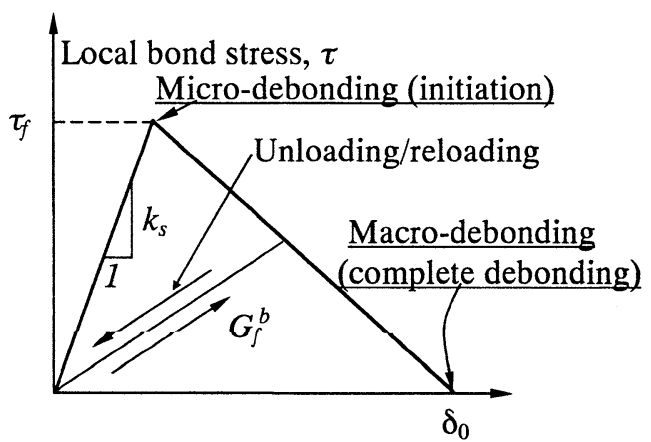

Local shear displacement, $\delta$

Fig. 6 Linear Softening Model for FRP-concrete Interface

\section{(3) FRP-Concrete Interface Model}

In the FRP-strengthened R/C beams, FRP sheets are mainly loaded primarily in tension and the interface layer is mainly loaded in shear transmitting stresses and providing the composite action between concrete and FRP sheets. This follows that the debonding propagation is very similar to the mode-II fracture. Recent experiments ${ }^{1), 2)}$ showed that the local interfacial shear stress distribution, effective bonding length, and initiation and propagation of interfacial crack could be well described by a linear softening shear-displacement model as shown in Fig. 6. When the local bond stress attains the local bond strength $\tau_{f}$, micro-debonding (softening) is initiated and afterwards the local bond stress decrease till it becomes zero. Macro-debonding (complete debonding) is formed when no bond stress is transferred or the energy required to create a unit area of debonding is met. The 
area below the curve is the fracture energy $G_{f}^{b}$. The scheme of unloading and reloading is secant path. This model can be used to simulate whether debonding occurs within concrete substrate, or through adhesive layer, or between FRP and the adhesive, the difference only lies in the choice of three parameters: bond strength $\tau_{f}$, initial stiffness $k_{s}$ and the fracture energy $G_{f}^{b}$.

To add rubber modifier to adhesive layer or flexible layer between concrete and adhesive layer is equivalent to change the bond properties between FRP sheet and concrete, which can be modeled through changing the corresponding parameters in this model.

\subsection{Material Models}

In addition to the above interface models for concrete cracking, steel-concrete and FRP-concrete, mechanical behaviors of three constituent materials should also be properly taken into account.

\section{(1) Concrete}

In the present study, it is assumed that no crack occurs in the locations other than the prescribed cracks. For the prescribed cracks, discrete cracking model as described above is used to model the initiation and propagation of cracks, where the fracture energy $G_{f}^{c}$ is taken as a normal value of $0.12 \mathrm{~N} / \mathrm{mm}$. The response of the concrete is modeled by Drucker-Prager plasticity, where the internal friction angle $\phi$ is taken as $10^{\circ}$.

\section{(2) Reinforcing Bars}

Reinforcing bars are regarded as a linear elastic-perfectly plastic material, as shown in Fig. 7. The stress in reinforcing bars increase linearly with a slope of its elastic modulus $E_{s}$ till the yield strength $f_{y}$ is attained. After yielding, the stress keeps constant with increase of strain. In the analysis, von Mises yield criterion is adopted to model this behavior.

\section{(3) FRP Sheets}

FRP sheets generally behave in linear elastic fashion until rupture. Unlike steel, FRP sheets are anisotropic and cannot resist compression and bending but only tension stress along their longitudinal direction. The rupture of FRP sheets may result in sudden loss of load-carrying capacity of the whole structure. Here, a linear elasticity is assumed for FRP sheets in that rupture of FRP can be analyzed afterwards.

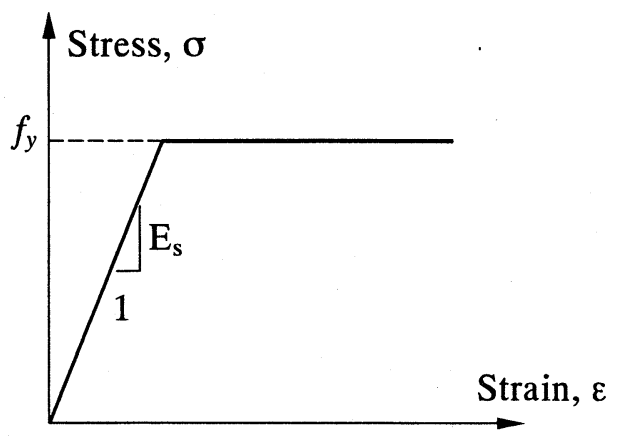

Fig. 7 Elastic-Perfectly Plastic Model for Steel

Table 1 Summary of the Material Properties

\begin{tabular}{|c|c|c|}
\hline Materials & Mechanical properties & Values \\
\hline \multirow{4}{*}{ Concrete } & Young's modulus (GPa) & 35.1 \\
\cline { 2 - 3 } & Compressive strength (MPa) & 49.3 \\
\cline { 2 - 3 } & Tensile strength (MPa) & 3.0 \\
\cline { 2 - 3 } & Poisson's ratio & 0.13 \\
\hline \multirow{2}{*}{$\begin{array}{c}\text { Steel } \\
\text { rebar }\end{array}$} & Young's modulus (GPa) & 210 \\
\cline { 2 - 3 } & Poisson's ratio & 0.3 \\
\hline D16 & Yielding strength (MPa) & 364 \\
\hline \multirow{3}{*}{$\begin{array}{c}\text { D13 } \\
\text { CFRP }\end{array}$} & Yielding strength (MPa) & 358 \\
\cline { 2 - 3 } sheets & Young's modulus (GPa) & 230 \\
\cline { 2 - 3 } & Tensile strength (GPa) & 4.1 \\
\cline { 2 - 3 } & Thickness (mm) & 0.111 \\
\cline { 2 - 3 } & Poisson's ratio & 0.3 \\
\hline
\end{tabular}

\section{Numerical Simulations}

Two possible crack patterns: one centralized flexural crack and many distributed flexural cracks are used to simulate the effects of adhesive properties on debonding behavior and structural performance. For the case of distributed crack pattern, determination of crack spacing $\mathrm{L}_{c}$ is a very complicated and may be related to many factors such as diameter of reinforcing bars, depth of concrete cover, FRP reinforcement stiffness, adhesive and concrete properties. According to Yoshizawa and $\mathrm{Wu}^{10)}$, average crack spacing of a flexural/CFRP sheets/steel bar specimen is only slightly affected by these factors and remains at about $70 \mathrm{~mm}$. Here crack spacings $L_{c}$ are taken as $56.3 \mathrm{~mm}$ and $75 \mathrm{~mm}$.

A FRP-strengthened RC beam subjected to three-point bending load is used to conduct numerical simulations on effects of adhesive properties on debonding behavior and FRP strengthening effects. The geometric and reinforcement details of the beam are shown in Fig. 2. It is $150 \mathrm{~mm}$ wide, $200 \mathrm{~mm}$ thick and $2100 \mathrm{~mm}$ long, with $170 \mathrm{~mm}$ long CFRP sheets bonded to its full width. Table 1 gives a summary of mechanical properties of the materials used in this study. 
Table 2 Adhesive Properties Investigated in Numerical Simulations

\begin{tabular}{|c|c|c|c|c|c|c|}
\hline \multirow{2}{*}{\multicolumn{2}{|c|}{ FRP-concrete bond behavior }} & \multirow{2}{*}{\multicolumn{2}{|c|}{ Crack patterns }} & \multicolumn{3}{|c|}{ Interfacial mechanical parameters } \\
\hline & & & & $k_{s}(\mathrm{MPa} / \mathrm{mm})$ & $\tau_{f}(\mathrm{MPa})$ & $G_{f}^{b}(\mathrm{~N} / \mathrm{mm})$ \\
\hline \multirow{12}{*}{$\tau_{f}^{\tau}$} & \multirow{4}{*}{$k_{s}(\mathrm{MPa} / \mathrm{mm})$} & \multirow{12}{*}{$\begin{array}{l}\text { One crack } \\
\text { (midspan) }\end{array}$} & \multirow{12}{*}{$\begin{array}{l}\text { Uniformly } \\
\text { distributed } \\
\text { cracks } \\
L_{c}=56.3 \mathrm{~mm}\end{array}$} & 2 & \multirow{4}{*}{2} & \multirow{8}{*}{1.2} \\
\hline & & & & 5 & & \\
\hline & & & & 25 & & \\
\hline & & & & 125 & & \\
\hline & \multirow{4}{*}{$\tau_{f}(\mathrm{MPa})$} & & & \multirow{4}{*}{5} & 0.5 & \\
\hline & & & & & 1 & \\
\hline & & & & & 2 & \\
\hline & & & & & 3 & \\
\hline & \multirow{4}{*}{$G_{f}^{b}(\mathrm{~N} / \mathrm{mm})$} & & & \multirow{4}{*}{5} & \multirow{4}{*}{2} & 0.6 \\
\hline & & & & & & 0.8 \\
\hline & & & & & & 1.2 \\
\hline & & & & & & 1.8 \\
\hline & \multirow{4}{*}{$\delta$} & \multirow{4}{*}{$\begin{array}{l}\text { One crack } \\
\text { (midspan) }\end{array}$} & \multirow{4}{*}{$\begin{array}{l}\text { Uniformly } \\
\text { distributed } \\
\text { cracks } \\
L_{c}=75 \mathrm{~mm}\end{array}$} & 10 & \multirow{4}{*}{-} & \multirow{4}{*}{-} \\
\hline & & & & 100 & & \\
\hline & & & & 1000 & & \\
\hline & & & & $1.0 \mathrm{E} 6$ & & \\
\hline
\end{tabular}

In this section, Diana finite element program ${ }^{11)}$ is adopted to perform the analysis of the FRP-strengthened $\mathrm{RC}$ beams.

Due to symmetry of the whole structure, only half of the beam is analyzed with appropriate boundary conditions and the applied load, as shown in Fig. 3. The retrofitted beam is loaded by a fixed displacement in Y-direction at the top of the mid-span. The thick lines represent FRP sheets, reinforcing bars and interfaces for FRP-concrete, flexural crack planes and reinforcing bar-concrete, respectively. Concrete beam is modeled with 4-node plane stress elements, reinforcing bars and FRP sheets are modeled with 2-node linear truss elements connected to concrete by zero-thickness interface elements. The vertical flexural cracks are modeled by zero-thickness interface elements at the locations spacing at a certain distance $L_{c}$ from the mid-span to the support of the beam. The corresponding mechanical behaviors can be introduced in the material definitions.

To clarify the experimental results ${ }^{6), 7)}$, in what follows, an effort is made to investigated effects of adhesive properties such as stiffness $k_{s}$, local bond strength $\tau_{f}$ and fracture energy $G_{f}^{b}$ on the FRP strengthening effects. According to Yoshizawa et al. ${ }^{2}$, the identified interfacial fracture energy normally ranges from 0.6 to $1.8 \mathrm{~N} / \mathrm{mm}$. These values are used in this study. The detailed parameters are shown in Table 2.

\subsection{Interfacial Stiffness $\boldsymbol{k}_{\boldsymbol{s}}$}

By fixing the other two parameters as $\tau_{f}=2 \mathrm{MPa}$ and $G_{f}^{b}=1.2 \mathrm{~N} / \mathrm{mm}$, several different stiffness values of
FRP-concrete interface are taken to compare the corresponding effects on load-carrying capacity, yield of reinforcing bars and stress distributions. It is found that for one localized crack pattern, the yield load may be decreased with decrease of the interfacial stiffness and stiffness only has an effect on the load prior to initiation of macro-debonding but the cracking load and the final load-carrying capacity remains the same in spite of different stiffness, as shown in Fig. 8. Low stiffness may make reinforcing bars early to yield due to the fact that low stiffness results in low transmission capacity of the adhesive layer and only after yield of reinforcing bars FRP stress can be increased very quickly, which also means that low stiffness may delay the occurrence of micro-debonding as shown in Fig. 8b. Although shear transfer length can be slightly enlarged in the case of low stiffness (Fig. 9a), the maximum FRP stresses nearly remain same (Fig. 9b), which accounts for the same load-carrying capacity. To give an intuitional knowledge of debonding propagation, distributions of interfacial shear stress and FRP axial stress are depicted for the case of $k_{s}=5 \mathrm{MPa} / \mathrm{mm}$ in Fig. 10. Once macro-debonding is initiated, FRP stress increases no more and debonding failure is result in. For the case of distributed crack patterns, as shown in Fig. 11, due to very complicated interaction between cracks, it is found that no significant effect can be found on the structural performance. Fig. 11b shows that debonding is initiated and propagated from the crack next to the central but not the central one for this case, which is often observed in practical experiments. Some discussions on this aspect can be 


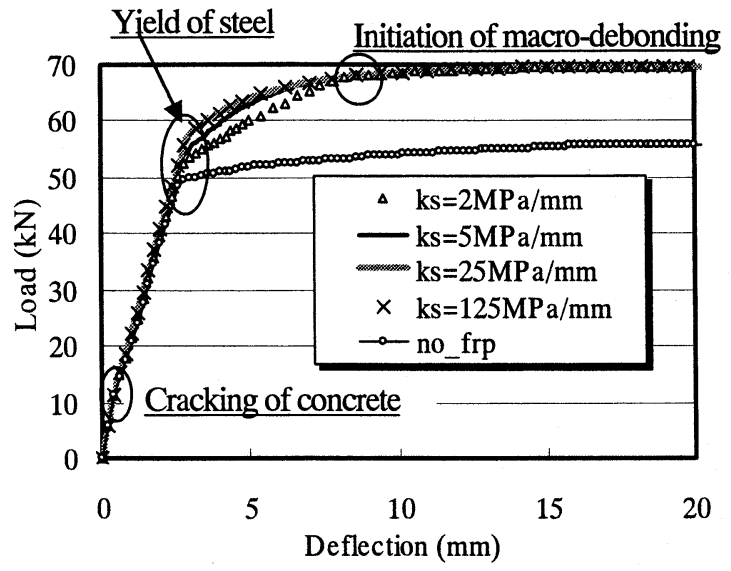

(a) Load vs. Deflection Curves

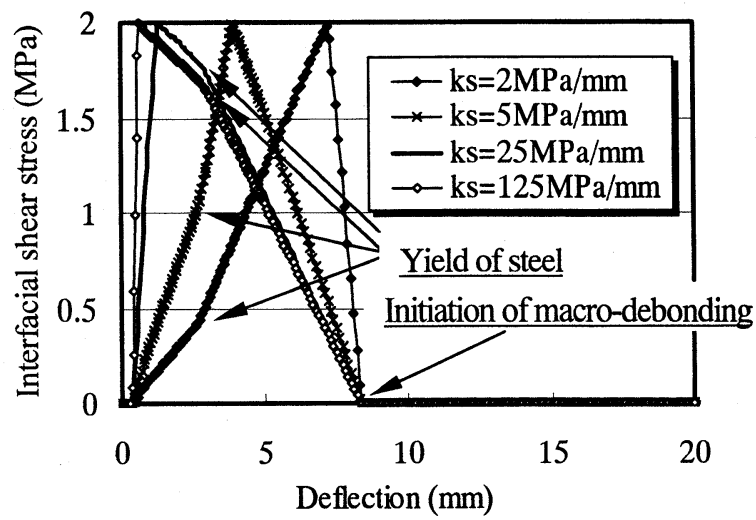

(b) Interfacial Shear Stress at Central Crack Location

Fig. 8 Structural Performances for Different Stiffnesses (One Crack at the Midspan)

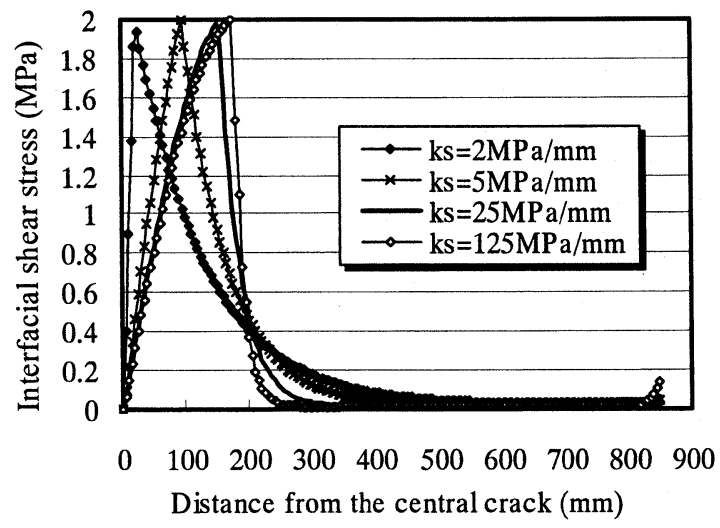

(a) Interfacial Shear Stresses

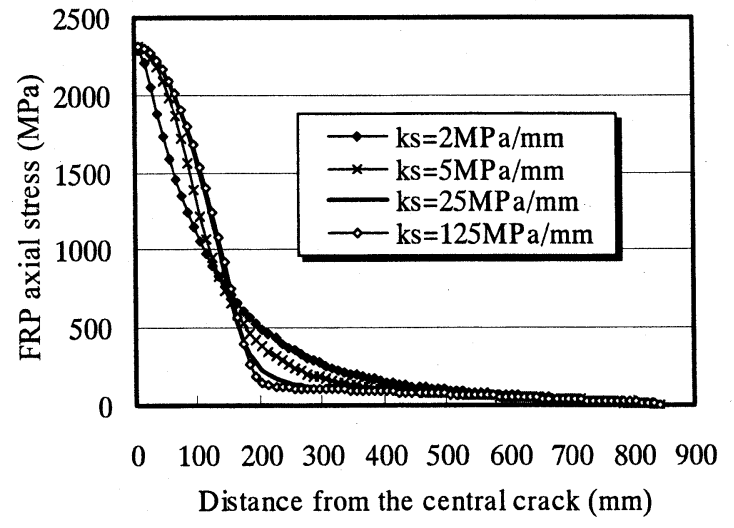

(b) FRP Axial Stresses

Fig.9Stress Distributions at Initiation of Macro-debonding (One Crack at the Midspan)

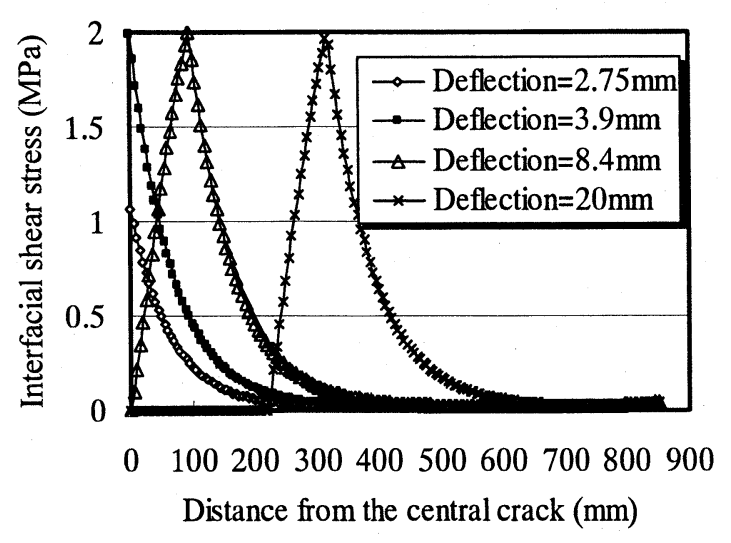

(a) Interfacial Shear Stresses

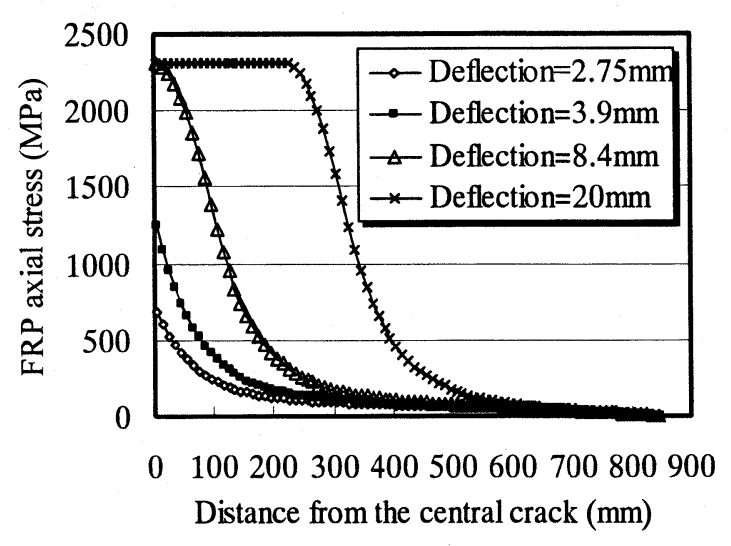

(b) FRP Axial Stresses

Fig. 10 Illustration of Debonding Propagations for the Case of $k_{s}=5 \mathrm{MPa} / \mathrm{mm}$ (One Crack at the Midspan)

referred to Niu and $\mathrm{Wu}^{5}$.

To further investigate the effect of stiffness on the strengthened RC beams with distributed cracks, a linear interfacial model without softening behavior is used. Seen from Fig. 12, it is confirmed that interfacial stiffness only affects yield load and has no effect on load-carrying capacity. For this case, the final failure mode is crushing of concrete due to the fact that no debonding is considered in the interfacial behavior.

\subsection{Local Bond Strength $\tau_{f}$}

By fixing the other two parameters as $k_{s}=5 \mathrm{MPa} / \mathrm{mm}$ and $G_{f}^{b}=1.2 \mathrm{~N} / \mathrm{mm}$, the structural performance and FRP 

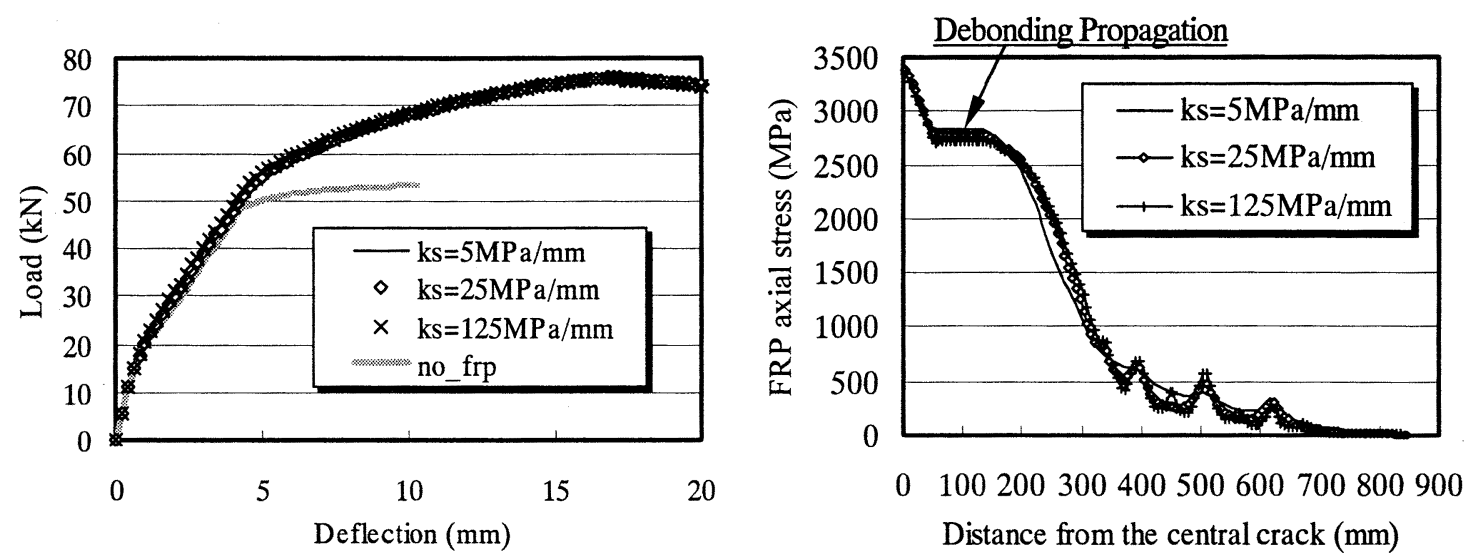

(a) Load vs. Deflection Curves

(b) FRP Axial Stress Distribution (Initiation of Macro-Debonding)

Fig. 11 Structural Performance for Different Stiffness (Distributed Cracks with $L_{c}=56.3 \mathrm{~mm}$ )

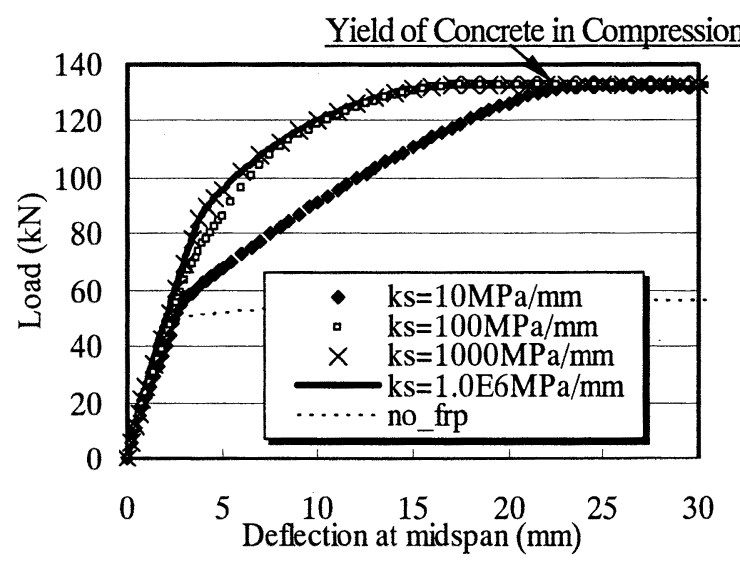

(a) One Crack at the Midspan

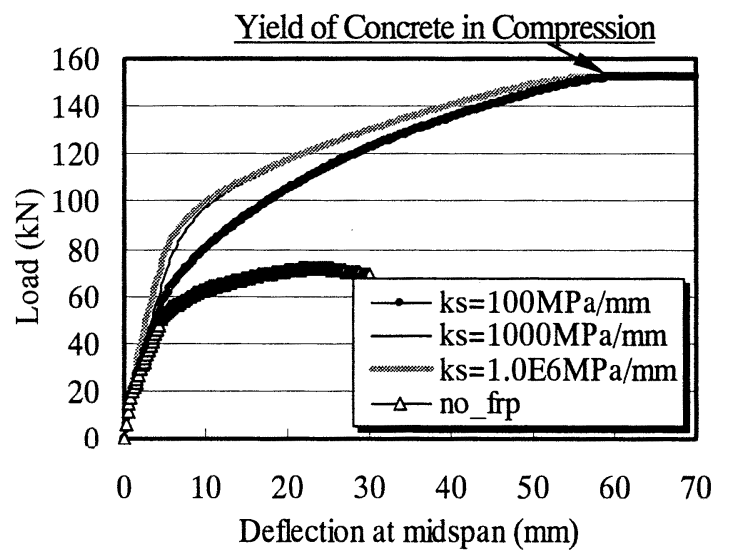

(b) Distributed Cracks with $L_{c}=75 \mathrm{~mm}$

Fig. 12 Load vs. Deflection Curves (Linear Bond Stress-Displacement Model without Softening)

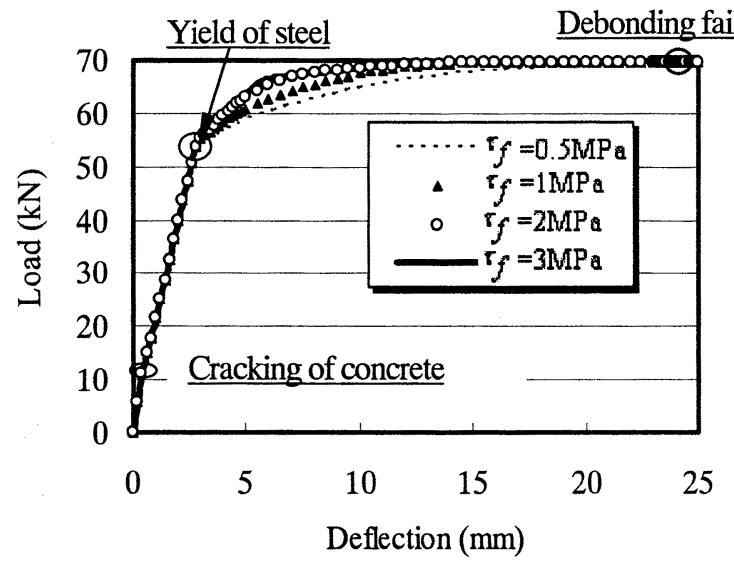

(a) Load vs. Deflection Curves

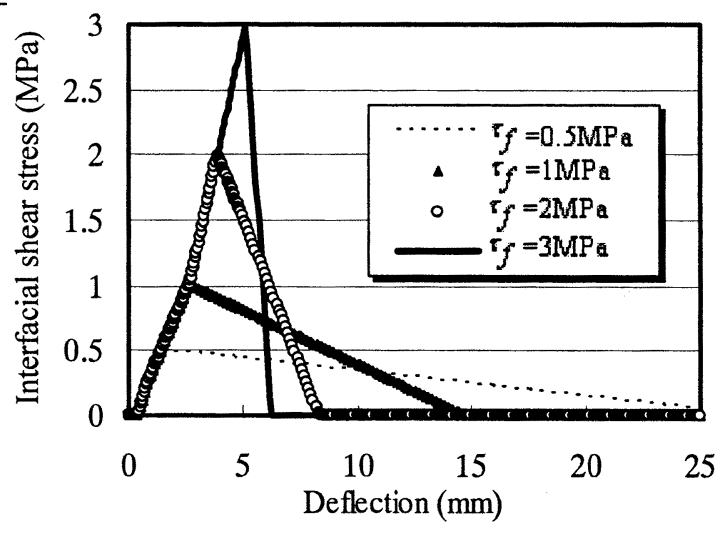

(b) Interfacial Shear Stress at Central Crack Location

Fig. 13 Structural Performances for Different Bond Strength (One Crack at the Midspan)

strengthening effects are investigated for different bond strengths of $0.5 \mathrm{MPa}, 1 \mathrm{MPa}, 2 \mathrm{MPa}$ and $3 \mathrm{MPa}$. For the case of one crack pattern, Fig. 13 shows that interfacial bond strength has no effect on yield load and only has slight effect on the structural behavior prior to initiation of macro-debonding. Low bond strength results in early occurrence of softening behavior in FRP-concrete interface and decreases the transmission capacity. But it may delay initiation of macro-debonding and thus avail to improve the ductility of structure. In Fig. 14, it can also be found that low bond strength can increase the effective transfer length and utilize the strengthening effects to the full. The bond capacity can be the same despite different local bond strengths. 


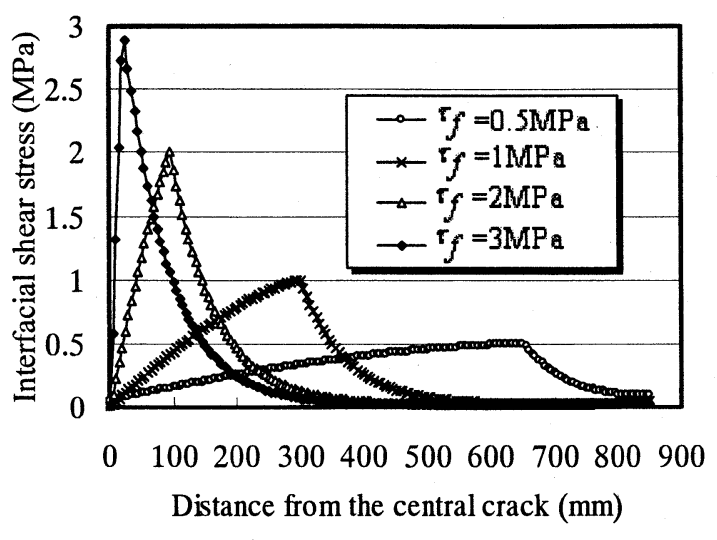

(a) Interfacial Shear Stresses

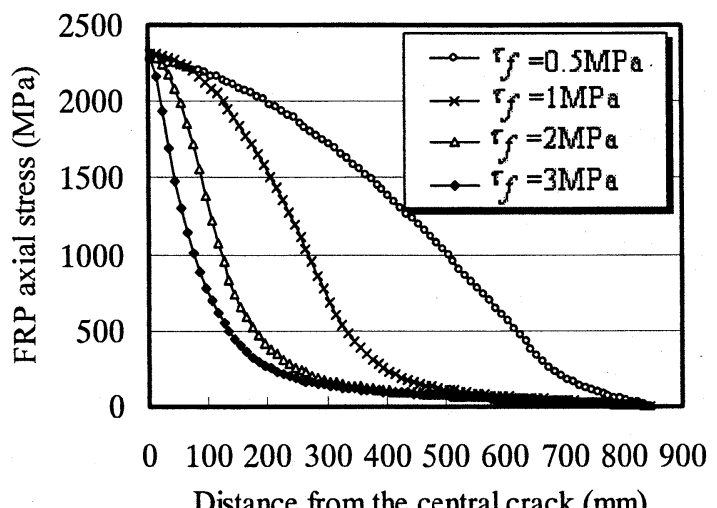

(b) FRP Axial Stresses

Fig. 14 Stress Distributions at Initiation of Macro-debonding (One Crack at the Midspan)

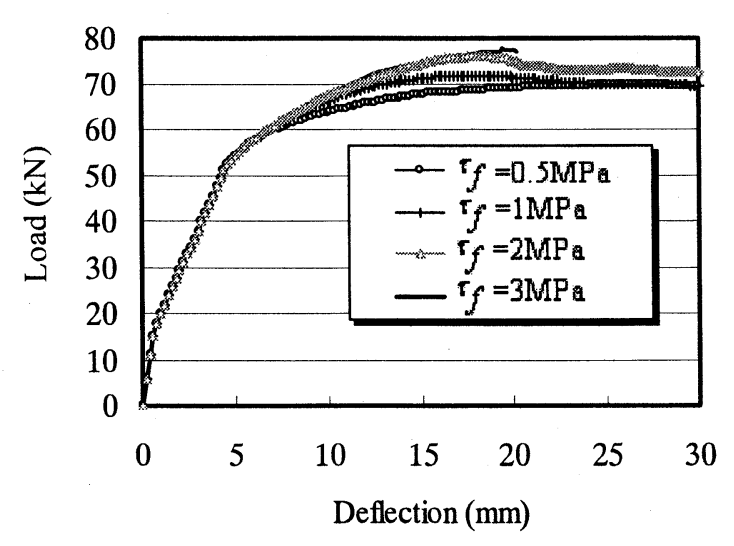

Fig. 15 Load vs. Deflection Curves for Different Bond Strengths (Distributed Cracks with $L_{c}=56.3 \mathrm{~mm}$ )

In Fig. 15, same results can be found in the case of distributed crack pattern, where divergency is encountered in the numerical computation for the case of $\tau_{f}=3 \mathrm{MPa}$. Low bond strength initiates early occurrence of micro-debonding and then yield of reinforcing bars, as shown in Fig. 16, whereas high bond strength delays the micro-debonding and makes reinforcing bars yield first. It should also be noted that different bond strength may

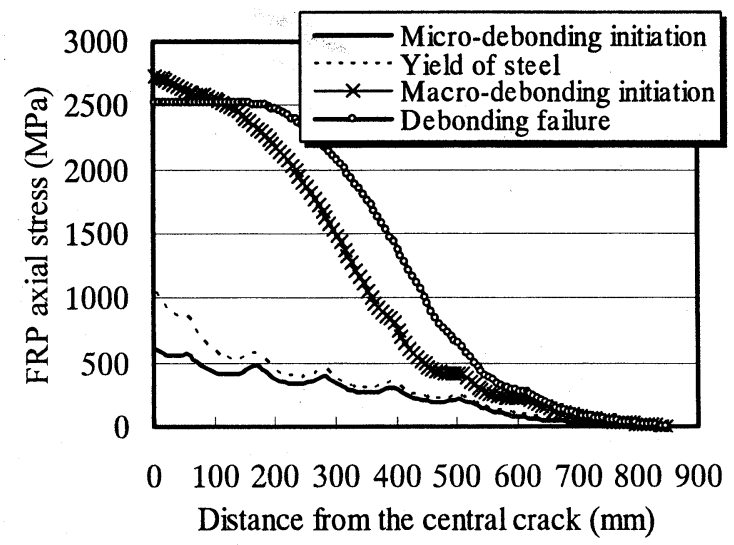

(a) Bond Strength $=1 \mathrm{MPa}$

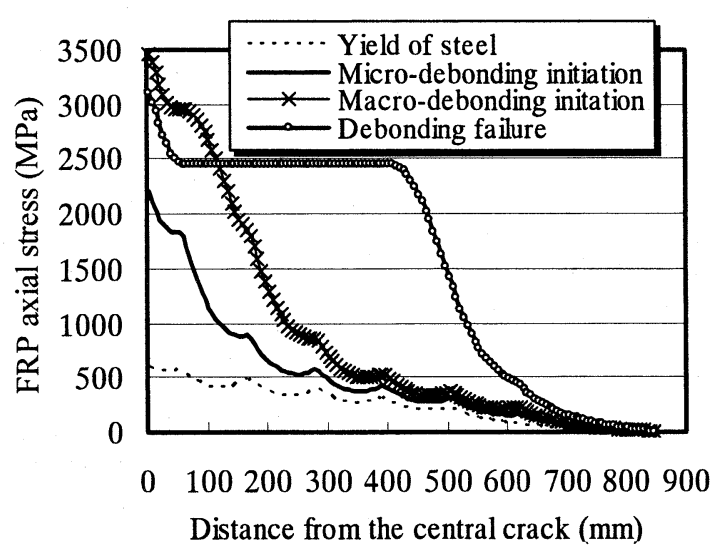

(b) Bond Strength $=2 \mathrm{MPa}$

Fig. 16 Debonding Propagations (Distributed Cracks with $L_{c}=56.3 \mathrm{~mm}$ )

affect the debonding failure modes. Low bond strength yields debonding failure initiated from the central crack, which may be due to its large transmission zone, whereas high bond strength results in debonding failure initiated from the crack next to the central.

\subsection{Interfacial Fracture Energy $\boldsymbol{G}_{\boldsymbol{f}}^{\boldsymbol{b}}$}

By fixing the other two parameters as $k_{s}=5 \mathrm{MPa} / \mathrm{mm}$ and $\tau_{f}=2 \mathrm{MPa}$, interfacial fracture energy is taken as $0.6 \mathrm{~N} / \mathrm{mm}, \quad 0.8 \mathrm{~N} / \mathrm{mm}, \quad 1.2 \mathrm{~N} / \mathrm{mm}$ and $1.8 \mathrm{~N} / \mathrm{mm}$, respectively to investigate its effect on the strengthening behavior for two possible crack patterns. In Fig. 17, it is shown that with increase of interfacial fracture energy the load-carrying capacity can be enhanced for both cases. As shown in Fig. 18, larger interfacial fracture energy may be helpful to increase the effective transfer length and then increase the bond capacity for the case of one crack pattern. For the case of distributed crack pattern, as shown in Fig. 19, interfacial fracture energy can affect the maximum achievable FRP stress, where debonding is initiated from the crack next to the central one. 


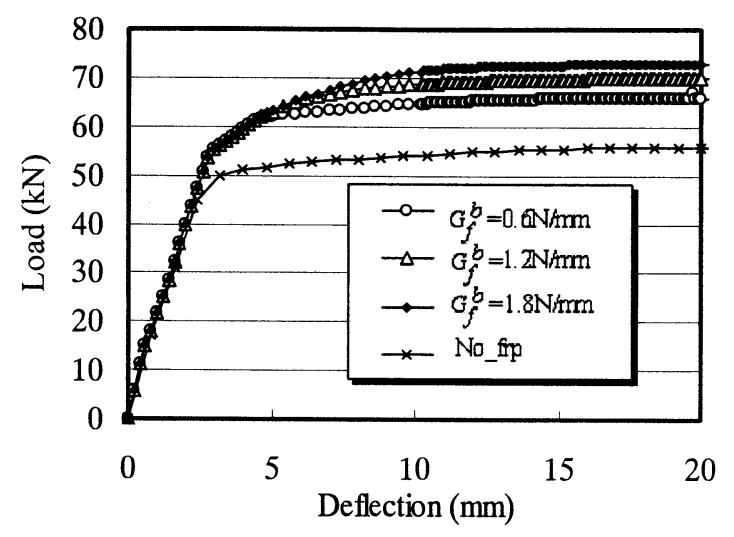

(a) One Crack at the Midspan

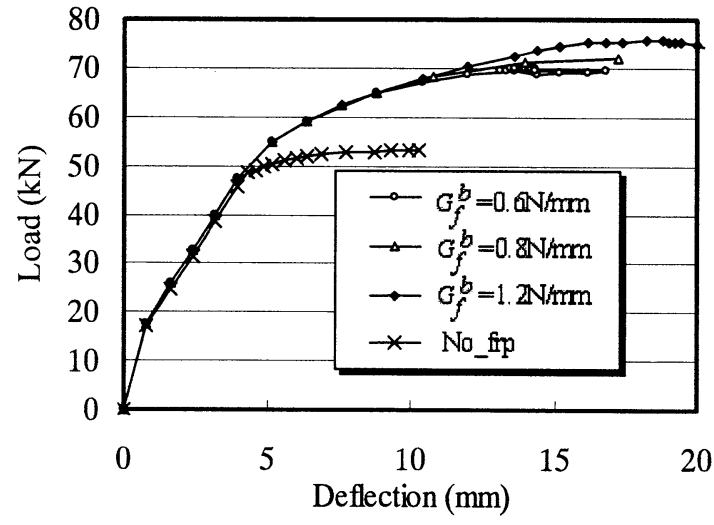

(b) Distributed Cracks with $L_{c}=56.3 \mathrm{~mm}$

Fig. 17 Load vs. Deflection Curves for Different Fracture Energies

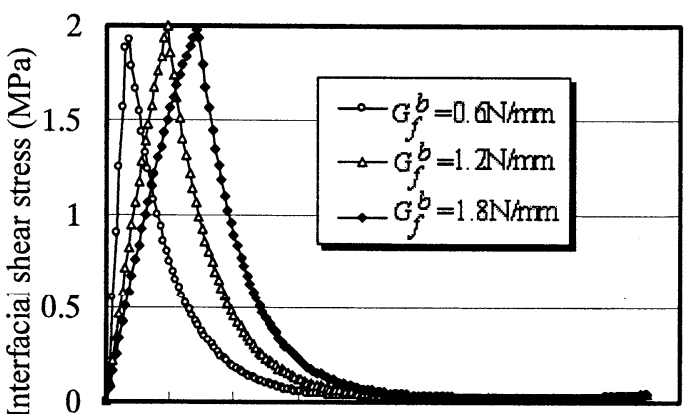

$0 \quad 100200300400500600700800900$ Distance from the central crack $(\mathrm{mm})$

(a) Interfacial Shear Stresses

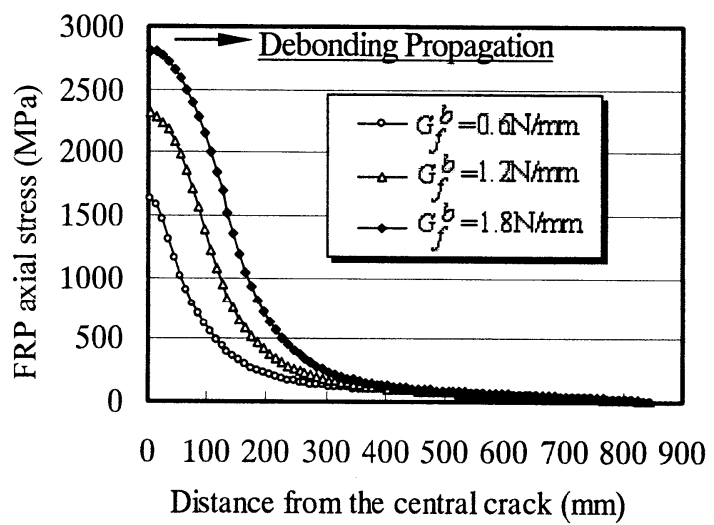

(b) FRP Axial Stresses

Fig. 18 Stress Distributions for One Crack at the Midspan (Initiation of Macro-debonding)

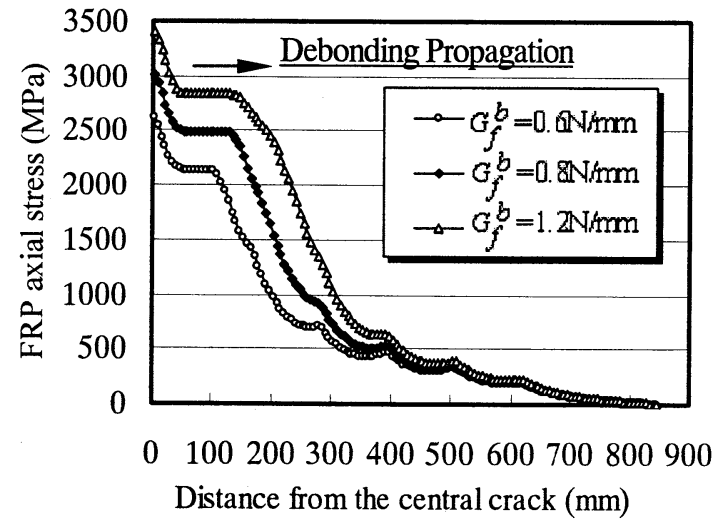

(a) Effect of Interfacial Fracture Energy (Debonding failure)

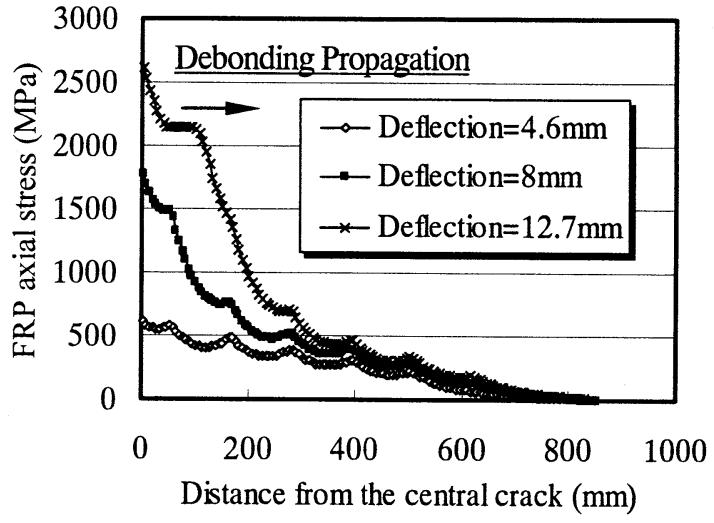

(b) Stress Development in FRP Sheet $\left(G_{f}=0.6 \mathrm{~N} / \mathrm{mm}\right)$

Fig. 19 Distributed Crack Pattern with $L_{c}=56.3 \mathrm{~mm}$

\section{Conclusions}

In response to the recent experiments by adding flexible layer between concrete and epoxy adhesive or rubber modifier to epoxy adhesive to improve FRP strengthening effects, this study gives a clear insight into the influencing mechanisms of the adhesive properties such as stiffness, bond strength and fracture toughness (i.e. interfacial fracture energy) from the viewpoint of nonlinear fracture mechanics. By using discrete crack model to simulate crack propagation of concrete, more realistic model with softening behavior to model bond behavior of the adhesive, the following conclusions can be drawn from the numerical simulations on the two 
possible crack patterns accompanied by debonding failure:

(1) Interfacial stiffness may affect yield load and the load prior to complete debonding. Low stiffness may decrease the yield load and delay the occurrence of softening, but have no effect on the ultimate load-carrying capacity.

(2) Bond strength may affect the load before initiation of complete debonding but have no effect on yield load and the load-carrying capacity. Low bond strength may increase the effective transfer length and thus utilize strengthening effects of FRP sheets to the full. Complete debonding may be delayed in the case of low bond strength, which implies that low bond strength may increase the ductility of the structure. It is also found that different bond strength may result in different debonding modes: where debonding propagation is initiated is shifted from the central crack for the low bond strength to the crack next to the central one for the high bond strength as shown in Fig. 16.

(3) Interfacial fracture energy or fracture toughness is the only parameter to govern the ultimate load-carrying capacity. Any measure that aims to improve FRP strengthening effects should be taken to increase the corresponding fracture energy of adhesive.

Based on the above discussions, it is not hard to explain some unsatisfactory experimental results ${ }^{6), 7)}$, which can be attributed to whether interfacial fracture energy is increased or not by adding flexible material to vary adhesive properties.

\section{Acknowledgements}

The writers gratefully acknowledge the partial financial support from the National High Technology Research and Development Program of China (863 Program, Grant Reference Number 2001AA336010).

\section{REFERENCES}

1) Nishida, H., Kamiharako, A., Shimomura, T. and Maruyama, $\mathrm{K}$.: Bond mechanism between continuous fiber and concrete,
Proceedings of the Japan Concrete Institute, 21(3), pp.1507-1512, 1999 (in Japanese).

2) Yoshizawa, H., Wu, Z. S., Yuan, H. and Kanakubo, T.: Study on FRP-Concrete Interface Bond Performance, Journal of Material, Concrete Structures and Pavements, JSCE, 49(662), pp.105-119, 2000 (in Japanese).

3) Wu, Z. S. and Niu, H. D.: Shear Transfer along FRP-Concrete Interface in Flexural Members, Journal of Material, Concrete Structures and Pavements, JSCE, 49(662), pp.231-245, 2000.

4) Wu, Z.S. and Niu, H.D.: Study on Debonding Failure Load of RC Beams Strengthened with FRP Sheets, Journal of Structural Engineering, JSCE, Vol.46A, 1431-1441, 2000.

5) Niu, H. D. and Wu, Z. S.: Debonding and Fracture Mechanics of FRP-Strengthened R/C Beams Influenced by Flexural Cracks, Submitted to Journal of Composites for Construction, ASCE.

6) Maeda, T., Komaki, H., Tsubouchi, K. and Murakami, K.: Strengthening behavior of carbon fiber sheet using flexible layer, Proceedings of the Japan Concrete Institute, 23(1), pp.817-822, 2001 (in Japanese).

7) Gao, B., Leung, W. H., Cheung, C. M., Kim, J.-K. and Leung, C. K. Y.: Effects of adhesive properties on strengthening of concrete beams with composite strips, International Conference on FRP Composites in Civil Engineering, Vol. 1, pp.423-432, 2001.

8) Hillerborg, A., Modeer, M. and Petersson, P. E.: Analysis of Crack Formation and Crack Growth in Concrete by Means of Fracture Mechanics and Finite Elements, Cement and Concrete Research, 6(6), pp.773-782, 1976.

9) Morita, S., Muguruma, H. and Tomita, K.: Fundamental Study on Bond between Steel and Concrete, Transaction of AIJ, 131(1), pp.1-8, 1967 (in Japanese).

10)Yoshizawa, H. and Wu, Z. S.: Cracking Behavior of Plain Concrete and Reinforced Concrete Members Strengthened with Carbon Fiber Sheets, Fourth International Symposium on Fiber Reinforced Polymer Reinforcement for Reinforced Concrete Structures, ACI International SP-188, pp.767-779, 1999.

11)DIANA-7 User's Manual., TNO Building and Construction Research, Lakerveld b.v., The Hague, 1998. 